\title{
Diagnostic sérologique de la fasciolose bovine à Fasciola gigantica par un test Elisa en Mauritanie
}

\author{
A. Bent Mohamed ${ }^{1}$ D. Cheikh ${ }^{2}$ \\ E. Thiam ${ }^{2}$ P. Jacquiet ${ }^{3} *$
}

\section{Mots-clés}

Bovin - Fasciola gigantica Test Elisa - Enquête pathologique Epidémiologie - Fleuve Sénégal Mauritanie.

\section{Résumé}

Depuis la mise en eau des barrages de Diama et de Manantali sur le fleuve Sénégal, les trématodoses du bétail, dont la fasciolose à Fasciola gigantica, ont connu une recrudescence importante. Un test de dépistage sérologique par Elisa qui utilise comme antigène les produits d'excrétion-sécrétion des douves adultes a été développé. Les résultats de ce test ont été comparés à la recherche directe de douves adultes dans les canaux biliaires chez 176 bovins abattus dans la basse vallée du fleuve. Parmi les 40 bovins porteurs de douves adultes, 39 ont été positifs en Elisa. Par ailleurs, 24 bovins ont présenté des titres en anticorps élevés sans douves adultes dans leurs canaux biliaires. Pour 22 de ces 24 animaux, l'abattage a eu lieu entre mars et juillet, période pendant laquelle les bovins s'infestent, suggérant ainsi que l'essentiel des cas de discordance entre le diagnostic par Elisa et la recherche de douves adultes provenait d'un dépistage précoce de l'infestation par la méthode Elisa. La plupart des animaux présentant une infestation monospécifique par d'autres trématodes (Schistosoma bovis ou paramphistomes) n'ont pas eu d'anticorps anti- $F$. gigantica. Le suivi sérologique et coproscopique d'une cohorte de veaux soumis à une infestation naturelle à proximité du fleuve Sénégal a permis de confirmer que la période d'infestation a lieu de mars à juillet. De plus, une enquête transversale sur 15 troupeaux de bovins de la basse vallée du fleuve a permis de montrer que les deux tiers de ces troupeaux étaient infestés avec des prévalences sérologiques variant de 13 à 33 p. 100.
1. Département de biologie, faculté des Sciences et techniques, BP 5026, Nouakchott, Mauritanie

2. Laboratoire de parasitologie, Centre national d'élevage et de recherches vétérinaires, BP 167, Nouakchott, Mauritanie

3. UMR Inra/Dger 1225, Ecole nationale vétérinaire de Toulouse,

23 chemin des Capelles, 31076 Toulouse Cedex 03, France

* Auteur pour la correspondance

Tél. : 0561193967 ; fax :0561 193944 ; e-mail :p.jacquiet@envt.fr

\section{INTRODUCTION}

Depuis la mise en eau des barrages de Diama et de Manantali sur le fleuve Sénégal, les conditions écologiques de la basse vallée du fleuve ont été profondément modifiées (eau plus douce, de $\mathrm{pH}$ neutre, très oxygénée et relativement stable toute l'année) favorisant ainsi la prolifération des mollusques hôtes intermédiaires de trématodes dont Limnaea natalensis, seul hôte intermédiaire connu de Fasciola gigantica en Afrique de l'Ouest (7). Les trématodoses du bétail, autrefois très rares ou absentes de la zone, $y$ sont maintenant bien établies, comme l'attestent des résultats d'abattoir de la ville de Rosso (capitale régionale du Trarza, basse vallée du fleuve Sénégal).

En zone tempérée comme en zone tropicale, le contrôle de la fasciolose bovine, respectivement à Fasciola hepatica et Fasciola gigantica, repose sur la détection de l'infestation des animaux. 
Une symptomatologie polymorphe et atypique rend difficile le diagnostic clinique, aussi les examens complémentaires sont-ils indispensables. La mise en évidence d'œufs dans les matières fécales est un diagnostic de certitude. Toutefois, les techniques coproscopiques ne permettent pas de détecter les infestations pendant la période prépatente et manquent de sensibilité lors d'infestations de faibles intensités. C'est pourquoi des tests sérologiques ont été développés : fixation du complément (1), immunofluorescence indirecte (13) ou Elisa (4, 10, 17).

Dans cette étude, les auteurs ont développé un test Elisa de dépistage sérologique de la fasciolose bovine à Fasciola gigantica à l'aide des antigènes d'excrétion-sécrétion de douves adultes afin, d'une part, de préciser la période de contamination des animaux grâce à un suivi régulier d'une cohorte de veaux pendant deux années et, d'autre part, de préciser la prévalence de la fasciolose bovine dans différentes zones de la basse vallée du fleuve par une enquête transversale : vallée du fleuve stricto sensu de Diama à Podor et vallée fossile autour du lac de R'kiz. Avant d'appliquer le test Elisa à ces préoccupations épidémiologiques, une comparaison avec la recherche directe de douves adultes à l'autopsie a été effectuée sur des bovins abattus à l'abattoir de Rosso.

\section{MATERIEL ET METHODES}

\section{Mise au point du test Elisa}

\section{Obtention des produits d'excrétion-sécrétion de douves adultes (PESFg)}

Les douves adultes ont été récoltées à l'abattoir de Rosso sur des foies de bovins infestés naturellement. Cinq lavages rapides dans du sérum physiologique (5-10 min/lavage) ont été nécessaires pour éliminer les impuretés qui entouraient les parasites (sang, bile, tissu hépatique). Ensuite, les douves ont été placées dans de l'eau distillée pendant $3 \mathrm{~h}$ à la température ambiante. Le liquide a ensuite été récupéré, filtré (diamètre $=45 \mu \mathrm{m}$ ) de façon à retirer les œufs, puis centrifugé à $3000 \mathrm{~g}$ pendant 15 min pour éliminer les débris, et stérilisé (azide de sodium, 0,05 p. 100). Les produits d'excrétion-sécrétion de douves adultes (PESFg) ont ainsi pu être obtenus. La concentration en protéines de cette solution a été déterminée en utilisant la technique du dosage des protéines à l'acide bicinchoninique (Pierce, Rockford, Illinois).

\section{Technique Elisa}

La mise au point du test Elisa a été celle décrite par Boulard et coll. (2) pour le diagnostic sérologique de la fasciolose à $F$. hepatica. Brièvement, différentes gammes de dilutions de sérum de $1 / 100$ à 1/500 ont été testées avec 10 sérums de bovins présentant des douves à l'abattage à l'abattoir de Rosso (témoins positifs) et 15 sérums de bovins provenant d'une zone du pays indemne de fasciolose et sur lesquels des examens coproscopiques répétés sur deux années se sont révélés négatifs (témoins négatifs). Les autres paramètres du test ont été fixes : concentration de l'antigène d'excrétion-sécrétion à $2,5 \mu \mathrm{g} / \mathrm{ml}$, conjugué anti-IgG $(\mathrm{H}+\mathrm{L})$ de bovin conjugué à la peroxydase au 1/40 000 (Jackson, USA). La dilution du sérum au 1/300 a été retenue car elle a permis d'obtenir un rapport optimal avec un bruit de fond minimum de la densité optique (DO) des positifs sur la densité optique des négatifs.

Les plaques de microtitration (Nunclon Surface, NUNC, Danemark) ont été sensibilisées par dépôt de $100 \mu \mathrm{l}$ par puits d'antigène PESFg à $2,5 \mu \mathrm{g} / \mathrm{ml}$ en tampon carbonate $0,1 \mathrm{M}$ à pH 9,6. Elles ont été incubées $1 \mathrm{~h}$ à $37^{\circ} \mathrm{C}$ puis une nuit à $4{ }^{\circ} \mathrm{C}$. Après quatre lavages avec du PBS-Tween 0,1 p. 100, les plaques ont été saturées par dépôt de $200 \mu \mathrm{l}$ par puits de tampon carbonate $\mathrm{pH}$ 9,6 additionné de gélatine à 0,5 p. 100 pendant $1 \mathrm{~h}$ à $37^{\circ} \mathrm{C}$. Le liquide a été éliminé et les sérums témoins (mélange des 10 positifs et mélange des 15 négatifs) et les sérums à tester dilués au 1/300 dans du PBST ont été déposés dans trois puits, à raison de $100 \mu \mathrm{l}$ par puits, puis incubés $1 \mathrm{~h}$ à $37^{\circ} \mathrm{C}$.

Après trois lavages en PBS-Tween 0,1 p. 100, le conjugué antibovin $\operatorname{IgG}(\mathrm{H}+\mathrm{L})$ a été déposé à raison de $100 \mu \mathrm{l}$ par puits et incubé $1 \mathrm{~h}$ à $37^{\circ} \mathrm{C}$. Après trois lavages en PBS-Tween 0,1 p. 100, puis deux lavages en PBS, la révélation a été obtenue par une solution de 2,2'-azino-bis-3-éthylbenzthiazoline-6-sulfonic acide (Sigma, St Louis, USA), en présence d'eau oxygénée et en tampon citrate $\mathrm{pH} 4$ (100 $\mu \mathrm{l}$ par puits). Après $1 \mathrm{~h}$ d'incubation à $37{ }^{\circ} \mathrm{C}$, l'intensité de la réaction colorée a été mesurée au spectrophotomètre (Diagnostic Pasteur, LP 400) à 405 nm.

La valeur relative de chaque sérum à tester $(\mathrm{X})$ a été exprimée en pourcentage par rapport aux sérums standards positifs (mélange des 10 positifs) et négatifs (mélange des 15 négatifs) :

$$
\mathrm{X}(\mathrm{DO} \%)=\frac{\mathrm{DO} \text { sérum à tester }-\mathrm{DO} \text { témoin négatif }}{\mathrm{DO} \text { témoin positif }-\mathrm{DO} \text { témoin négatif }} \mathrm{X} 100
$$

\section{Validation du test Elisa}

Au cours d'une enquête mensuelle sur une durée totale de deux années, 176 bovins abattus à l'abattoir de Rosso (basse vallée du fleuve Sénégal où la fasciolose à Fasciola gigantica est endémique) ont été examinés. Pour chaque bovin, le sexe, l'âge et la race ont été notés. Une prise de sang et un prélèvement de matières fécales ont été réalisés avant l'abattage. A l'autopsie, les grandes douves adultes ont été recherchées dans les canaux biliaires, les paramphistomes adultes dans le rumen et les schistosomes dans les veines mésentériques. Les résultats de l'analyse sérologique ont été comparés aux résultats de la recherche directe des parasites.

\section{Etude épidémiologique de la fasciolose par la technique Elisa}

\section{Suivi d'une cohorte de veaux}

Pour mieux préciser la période d'infestation des bovins dans la basse vallée du fleuve Sénégal, 10 veaux âgés de 15 à 45 jours ont été identifiés par des boucles à l'oreille au mois de mars 1995 dans le village de Tounguène situé sur un bras du fleuve Sénégal. Les éleveurs de cette zone maintenaient leurs veaux dans des enclos près du village jusqu'à l'âge de trois mois. Durant toute cette période, ils n'étaient donc pas soumis au risque de contamination par $F$. gigantica. En revanche, à partir de trois mois, ils suivaient leur mère au pâturage et fréquentaient alors les sites de transmission. Tous les deux mois, pendant deux ans, des prélèvements de fèces et de sang ont été effectués sur ces veaux. Un examen coproscopique quantitatif par sédimentation (16) de deux grammes de matières fécales et contre coloration au bleu de méthylène a été pratiqué sur chacun des veaux pendant la période de l'étude. Les œufs jaunes de Fasciola gigantica ont été facilement repérés à la loupe binoculaire (x 50) sur le fond bleu. Ils se sont distingués facilement des œufs blancs de paramphistomes.

\section{Enquête transversale dans des troupeaux bovins de la basse vallée du fleuve Sénégal}

Cette enquête a été réalisée au mois de juillet 1998 dans 15 élevages de la basse vallée du fleuve Sénégal répartis en amont du barrage de Diama à Leksaiba (Podor) afin de connaître la prévalence de la fasciolose dans cette région (figure 1). La taille moyenne des troupeaux a été de 40 têtes. Le nombre d'animaux prélevés a varié de 21 à 48 selon la bonne volonté du propriétaire. Les animaux ont été répartis en nombre équivalent en trois classes d'âge $(<2$ ans, 2-3 ans, $>3$ ans). Sur chaque animal 


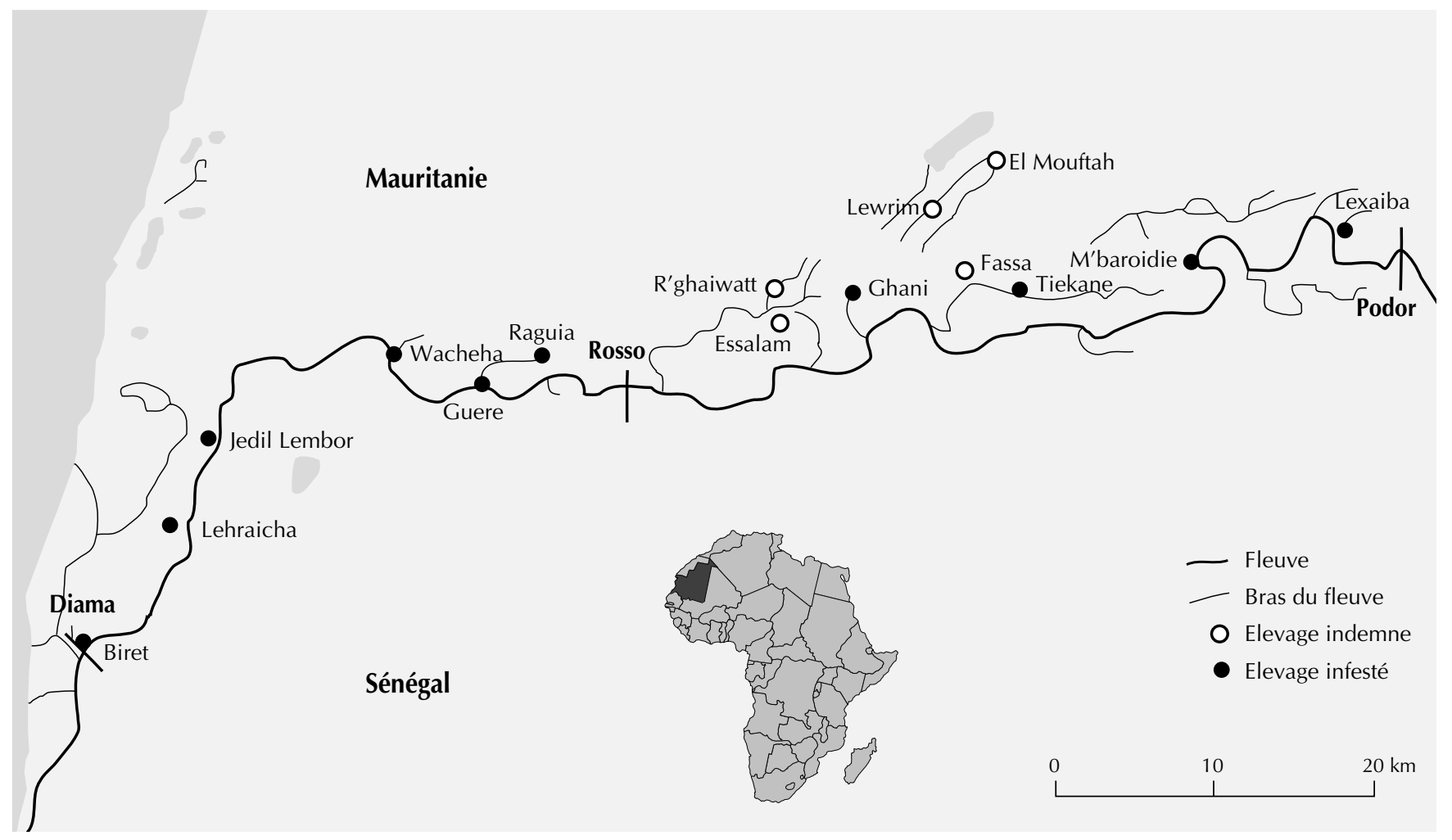

Figure 1 : répartition géographique des élevages bovins de l'enquête sérologique transversale de juillet 1998.

un prélèvement de fèces et une prise de sang ont été réalisés. Au total 479 prélèvements ont été effectués. Les examens coproscopiques réalisés ont été identiques à ceux effectués sur les veaux.

\section{RESULTATS}

\section{Détermination du seuil de positivité}

Le seuil de positivité a été fixé à la moyenne des densités optiques des sérums négatifs plus trois fois l'écart-type des DO de ces sérums, soit une valeur de 0,181 . Cette valeur de densité optique correspondait à 25 p. 100 de la densité optique du mélange de sérums positifs. Le seuil de positivité a donc été fixé à 25 p. 100 de la valeur de DO du mélange de sérums positifs.

\section{Correspondance entre résultats d'autopsie et analyse sérologique par Elisa}

La comparaison des résultats de recherche directe des douves adultes dans les foies des animaux abattus à l'abattoir de Rosso et ceux de l'analyse sérologique par Elisa est présentée dans le tableau I. Le test Elisa a permis de détecter 39 des 40 animaux présentant des douves adultes à l'abattage, soit une sensibilité de 97,5 p. 100. En outre, le test Elisa a permis de détecter 24 autres animaux positifs alors qu'ils ne présentaient pas de douves adultes à l'observation macroscopique. Sur l'ensemble de la période étudiée, le test du Chi-2 a montré que les deux tests n'étaient pas équivalents $(\mathrm{P}<0,001)$. La plus grande partie des cas de discordance entre le test Elisa et la recherche de douves adultes dans le foie (22 cas sur 24) s'est située entre mars et août. Les deux tests ont été équivalents entre septembre et février, discordants $(\mathrm{P}<0,001)$ entre mars et août.

D'autre part, il y a eu très peu de réactions croisées avec les autres espèces de trématodes. En effet, la plupart des animaux infestés par Schistosoma bovis ou par les paramphistomes (infestations uniques ou mixtes), soit 55 cas sur 59, ont présenté des titres en anticorps

\section{Tableau I}

Correspondance entre les résultats d'autopsie et I'analyse sérologique par Elisa chez les animaux abattus à Rosso au cours de la période février 1995 - mars 1997

\begin{tabular}{|c|c|c|c|c|c|}
\hline & \multirow[b]{2}{*}{ Nb. d'animaux } & \multicolumn{2}{|c|}{ Présence de douves } & \multicolumn{2}{|c|}{ Elisa } \\
\hline & & + & $\%$ & + & $\%$ \\
\hline Fév. 95 & 7 & 0 & 0 & 0 & 0 \\
\hline Mars 95 & 8 & 0 & 0 & 1 & 13 \\
\hline Avr. 95 & 14 & 1 & 7 & 4 & 29 \\
\hline Mai 95 & 11 & 1 & 9 & 3 & 27 \\
\hline Juin 95 & 6 & 1 & 17 & 1 & 17 \\
\hline Juil. 95 & 6 & 1 & 17 & 2 & 33 \\
\hline Sept. 95 & 13 & 4 & 31 & 4 & 31 \\
\hline Oct. 95 & 6 & 1 & 17 & 1 & 17 \\
\hline Nov. 95 & 7 & 1 & 14 & 3 & 43 \\
\hline Déc. 95 & 6 & 2 & 33 & 2 & 33 \\
\hline Jan. 96 & 7 & 2 & 29 & 2 & 29 \\
\hline Fév. 96 & 7 & 2 & 29 & 1 & 14 \\
\hline Mars 96 & 13 & 4 & 31 & 4 & 31 \\
\hline Avr. 96 & 14 & 4 & 29 & 9 & 64 \\
\hline Juil. 96 & 8 & 3 & 38 & 7 & 88 \\
\hline Août 96 & 5 & 3 & 60 & 5 & 100 \\
\hline Oct. 96. & 9 & 3 & 33 & 3 & 33 \\
\hline Déc. 96 & 5 & 1 & 20 & 1 & 20 \\
\hline Fév. 97. & 5 & 1 & 20 & 1 & 20 \\
\hline Mars 97 & 19 & 5 & 26 & 9 & 47 \\
\hline
\end{tabular}

$\%$ : taux d'infestations obtenus par la coproscopie et par l'Elisa

+ : animal positif à l'examen coproscopique ou par l'Elisa 
anti-PESFg très faibles, de 2 à 17 p. 100. Quatre cas seulement (une infestation unique par S. bovis, une infestation unique par les paramphistomes et une infestation double $S$. bovis et paramphistomes) ont donné des titres d'anticorps élevés en juillet-août.

\section{Applications sur le terrain}

\section{Incidence de l'infestation par $\mathrm{F}$. gigantica chez les veaux exposés à l'infestation naturelle}

Les résultats obtenus chez les 10 veaux identifiés et suivis régulièrement pendant deux ans ont montré l'infestation de deux veaux au cours de la première année et de deux autres au cours de la deuxième année comme cela a été observé par la coproscopie et l'analyse sérologique par le test Elisa (figures 2 et 3). La séroconversion est intervenue plus précocement (juillet ou août) que l'apparition d'œufs de $F$. gigantica dans les selles (septembre à décembre). Ce résultat a été retrouvé pour les veaux 2 et 4 (première année) et 3 et 8 (deuxième année). Les veaux infestés ont conservé des titres en anticorps élevés tout au long de la période de

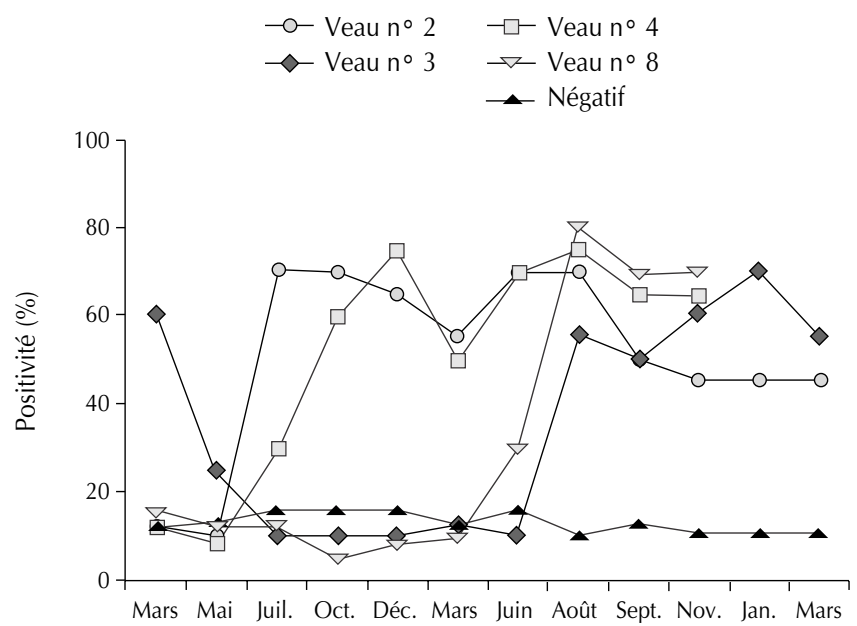

Figure 2 : cinétique d'apparition des anticorps anti-Fasciola gigantica chez les veaux infestés naturellement (seuil de positivité 25 p. 100).

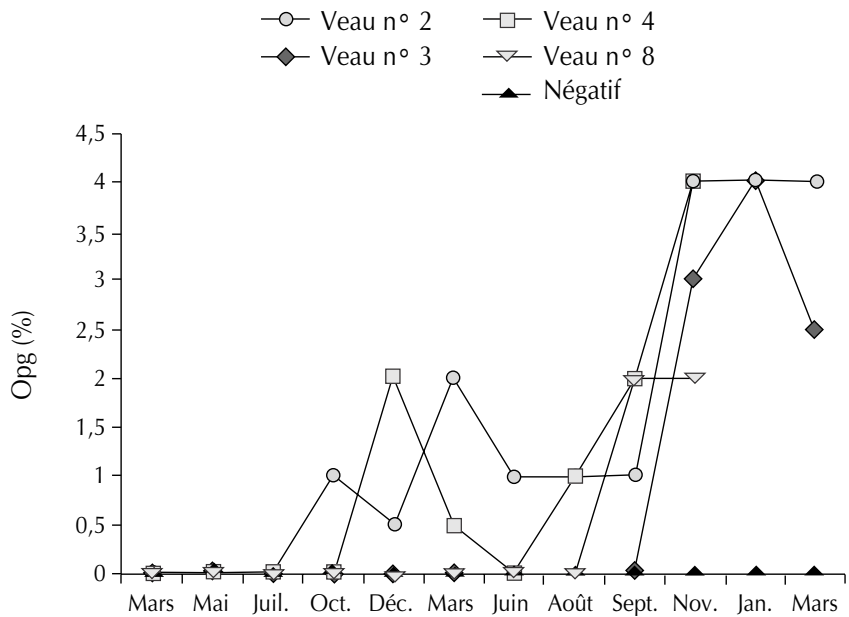

Figure 3 : cinétique d'apparition des œufs de Fasciola gigantica dans les matières fécales des veaux infestés naturellement (Opg = œufs par gramme de matières fécales). suivi. Le veau 3 a présenté des anticorps maternels décelables par le test Elisa à l'âge de 20 jours ; ces anticorps ont disparu à l'âge de deux mois. Il est donc souhaitable de réaliser le test Elisa sur des animaux de plus de deux mois. D'autre part, aucune réaction croisée n'a été remarquée avec les paramphistomes. En effet, les veaux présentant uniquement des infestations par les paramphistomes (veaux 6 et 9) ont conservé des titres anticorps anti$F$. gigantica très faibles.

\section{Enquête transversale dans des troupeaux bovins de la basse vallée du fleuve Sénégal}

Les résultats coproscopiques et sérologiques de l'enquête réalisée en juillet 1998 (tableau II) ont monté l'importance de la fasciolose au niveau de la région du Trarza. La technique Elisa et la coproscopie ont mis en évidence la fasciolose dans les mêmes élevages (10 troupeaux sur 15). La séroprévalence (16,5 p. 100) a été plus importante que la prévalence établie par la coproscopie (9,4 p. 100).

\section{DISCUSSION}

Le test Elisa développé dans ce travail a utilisé des antigènes d'excrétion-sécrétion de douves adultes. Ce type d'antigènes a été largement utilisé pour développer des tests de dépistage sérologique de la fasciolose à Fasciola hepatica $(3,5,18,19)$ dont la sensibilité s'est révélée plus importante que la mise en évidence des œufs du parasite dans les matières fécales. Ils peuvent être utilisés bruts, sans étape de purification biochimique. La recherche de communautés antigéniques entre les produits d'excrétion-sécrétion de $F$. hepatica et d'autres parasites de bovins (nématodes, cestodes, agents de myiases, d'autres trématodes comme la petite douve ou les paramphistomes) s'est révélée négative (3). Toutefois, certaines réactions croisées avec Schistosoma mansoni, agent de la bilharziose intestinale humaine, ont été signalées (15). Une approche similaire, à partir des produits d'excrétion-sécrétion

\section{Tableau II}

Prévalences de la fasciolose à Fasciola gigantica établies par sérologie Elisa et coproscopie dans 15 élevages de la basse vallée du fleuve Sénégal (juillet 1998)

\begin{tabular}{|c|c|c|c|c|c|}
\hline \multirow[b]{2}{*}{ Localité } & \multirow[b]{2}{*}{$\begin{array}{c}\mathrm{Nb} . \\
\text { d'animaux }\end{array}$} & \multicolumn{2}{|c|}{ Coproscopie } & \multicolumn{2}{|c|}{ Elisa } \\
\hline & & Positifs & $\%$ & Positifs & $\begin{array}{c}\% \text { de } \\
\text { positifs }\end{array}$ \\
\hline Biret & 35 & 4 & 11 & 6 & 17 \\
\hline Lehraicha & 36 & 6 & 17 & 7 & 19 \\
\hline Jedil Lembor & r 27 & 4 & 15 & 7 & 26 \\
\hline Wacheha & 43 & 9 & 21 & 13 & 30 \\
\hline Guere & 31 & 7 & 19 & 9 & 29 \\
\hline Raguia & 21 & 2 & 9 & 3 & 14 \\
\hline $\mathrm{R}^{\prime}$ ghaiwatt & 48 & 0 & 0 & 0 & 0 \\
\hline Essalam & 33 & 0 & 0 & 0 & 0 \\
\hline Ghani & 32 & 3 & 9 & 7 & 13 \\
\hline Fassa & 45 & 0 & 0 & 6 & 33 \\
\hline Tiekane & 39 & 5 & 13 & 9 & 23 \\
\hline M'baroidie & 28 & 2 & 7 & 7 & 23 \\
\hline Lexaiba & 27 & 3 & 15 & 5 & 19 \\
\hline Lewrim & 34 & 0 & 0 & 0 & 0 \\
\hline El Mouftah & 44 & 0 & 0 & 0 & 0 \\
\hline
\end{tabular}


des douves adultes, a été menée pour le sérodiagnostic de la fasciolose bovine à Fasciola gigantica (9). L'existence de communautés antigéniques entre $F$. gigantica, Dicrocoelium hospes et Schistosoma bovis (10) a cependant motivé la purification et la caractérisation d'une cystéine protéase immunogène dans les produits d'excrétion-sécrétion de $F$. gigantica adultes (11), utilisée ensuite en Elisa (12). Dans la présente étude à l'abattoir de Rosso, un très faible nombre d'animaux infestés par $S$. bovis ou par des paramphistomes (Carmyerius exoporus et Calicophoron microbothrium) ont présenté des pourcentages d'anticorps anti- $F$. gigantica élevés (4 bovins sur 59). La présence de Dicrocoelium hospes n'a pas pu être mise en évidence dans la présente étude. De plus, des veaux qui ont été contaminés au cours de leurs deux premières années par des paramphistomes seulement n'ont pas développé de réponse anticorps anti- $F$. gigantica décelable. Tous ces éléments indiquent que les réactions croisées ont dû être très limitées.

Un seul animal présentant des douves à l'autopsie n'a pas présenté de réponse anticorps décelable par le test Elisa. Ce phénomène a déjà été signalé par certains auteurs (2) et pourrait être expliqué par une diminution de la stimulation du système immunitaire de l'hôte lorsque les douves sont installées dans les canaux biliaires (14). Pour tous les autres bovins présentant des douves adultes à l'autopsie, le test Elisa a été positif même si aucune corrélation entre l'intensité de la réponse anticorps et le nombre de douves adultes récoltées n'a pu être mis en évidence.

Chez quatre veaux suivis dans la localité de Tounguène, la présence d'anticorps a été observée deux à quatre mois avant la mise en évidence des œufs de douves dans les matières fécales. Des résultats comparables ont été obtenus par Diaw et coll. (6) chez deux agneaux infestés expérimentalement par $F$. gigantica. Ils sont aussi en accord avec les travaux réalisés expérimentalement chez les bovins et les ovins infestés expérimentalement par $F$. hepatica $(3,8,20)$. Le test Elisa permet donc une détection plus précoce de l'infestation que l'examen coproscopique en raison de la longueur de la période prépatente de cette parasitose (10 à 12 semaines). De même, à l'abattoir, il est possible de ne pas détecter une infestation par des douves immatures dans le parenchyme hépatique des bovins. Dans ce cas, il y a discordance entre le résultat sérologique et l'examen nécropsique. Cette détection précoce de l'infestation par la technique Elisa pourrait être à l'origine des différences des taux d'infestation obtenus par les deux méthodes chez les animaux abattus. Les différences entre les deux tests dépendent étroitement de la saison de réalisation des prélèvements. Ainsi, les deux tests ont été équivalents entre septembre et février et très discordants (plus de cas positifs en Elisa qu'à l'examen nécropsique) entre mars et août. Or, dans une enquête épidémiologique sur les mollusques hôtes intermédiaires de trématodes dans la basse vallée du fleuve Sénégal, les auteurs ont observé que les densités maximales de mollusques et la libération de cercaires de $F$. gigantica par ces mollusques se situaient entre mars et juillet (résultats non publiés). La contamination des animaux se faisant uniquement à cette période de l'année, il est donc vraisemblable que les résultats positifs en Elisa sans douves adultes dans les canaux biliaires reflétaient des cas de contaminations récentes. Cette période de contamination pendant les mois de mars à juillet est corroborée par les périodes de séroconversion des veaux de Tounguène (juillet ou août).

L'enquête transversale sur 15 troupeaux bovins de la basse vallée du fleuve Sénégal a permis de confirmer la présence de cette parasitose dans cette zone d'élevage bovin du Sud mauritanien. Toutefois, on peut noter certaines différences selon la zone étudiée : les troupeaux situés entre le barrage de Diama et la ville de Rosso ont tous été infestés par $F$. gigantica. C'était également la zone où les populations de Limnaea natalensis étaient les plus abondantes.
En revanche, autour du lac de R'kiz, les populations de cette limnée étaient beaucoup plus limitées, ce qui pouvait expliquer l'absence de contamination chez les troupeaux qui y vivaient (troupeaux numéros 7, 8, 10, 14 et 15). La technique Elisa a permis aussi la détection des anticorps maternels chez les jeunes veaux. Ces anticorps disparaissent rapidement et ne confèrent pas au veau une immunité contre la fasciolose.

\section{- CONCLUSION}

Le test Elisa utilisant des antigènes d'excrétion-sécrétion de $F$. gigantica a permis d'identifier les animaux infestés naturellement et n'a présenté que très peu de réactions croisées avec les autres espèces de trématodes. La détection de l'infestation a été beaucoup plus précoce par cette méthode que par la coproscopie, ce qui explique la discordance entre les deux tests pendant la période de contamination des animaux.

La comparaison des résultats obtenus par les deux techniques indique que, dans le contexte épidémiologique de la basse vallée du fleuve Sénégal, la technique Elisa est la méthode de diagnostic de choix pour les prélèvements réalisés durant la période mars à juillet. En revanche, les deux tests sont équivalents entre septembre et février.

\section{BIBLIOGRAPHIE}

1. BLANCOU J., BOUCHET A., DAYNES P., 1971. Etude sur I'allergie, les anticorps précipitants et les anticorps fixant le complément au cours de l'infestation des bovins par Fasciola gigantica. Revue Elev. Méd. vét. Pays trop., 24 : 373-379.

2. BOULARD C., BOUVRY M., ARGENTE G., 1985. Comparaison de la détection des foyers de fasciolose par test Elisa sur lactosérum et par coproscopie. Ann. Rech. vét., 16 : 363-368.

3. BOULARD C., REGNAULT A., 1989. L'immunodiagnostic de la fasciolose bovine par méthode Elisa. Bull Groupe Rech. vét., 1B : 59-68.

4. BURDEN D.J., HAMMET N.C., 1978. Microplate enzyme-linked immunosorbent assay for antibody to Fasciola hepatica in cattle. Vet. Rec., 103: 158-161.

5. CHAUVIN A., MOREAU E., BOULARD C., 1997. Diagnostic de la fasciolose bovine par sérologie de mélange. Interprétation en conditions de terrain. Vet. Res., 28: 37-43.

6. DIAW O.T., SEYE M.M., SEYE M., SARR Y., VASSILIADES G., 1994. L'immunodiagnostic de la fasciolose à Fasciola gigantica par la technique Elisa au Sénégal. Observations préliminaires chez deux agneaux. Revue Elev. Méd. vét. Pays trop., 47 : 291- 294.

7. DIAW O.T., VASSILIADES G., THIONGANE Y., SEYE M., SARR Y. DIOUF A., 1998. Extension des trématodoses après la construction des barrages dans le bassin du fleuve Sénégal. Revue Elev. Méd. vét. Pays trop., $51:$ :113-120.

8. DOY T.G., HUGHES D.L., 1984. Early migration of immature Fasciola hepatica and associated liver pathology in cattle. Res. vet. Sci., 37: 219-222.

9. FAGBEMI B.O., OBARISIAGBON I.O. 1990. Comparative evaluation of the enzyme-linked immunosorbent assay (ELISA) for diagnosis of Fasciola gigantica infection in cattle. Vet. Q., 12: 35-38.

10. FAGBEMI B.O., OBARISIAGBON I.O., 1991. Common antigen of Fasciola gigantica, Dicrocoelium hospes and Schistosoma bovis and their relevance to serology. Vet. Q., 13: 81-87.

11. FAGBEMI B.O., HILLYER G.V., 1992. The purification and characterization of a cysteine protease of Fasciola gigantica adult worms Vet. Parasitol., 43: 223-232.

12. FAGBEMI B.O., GUOBADIA E.E., 1995. Immunodiagnosis of fasciolosis in ruminants using a 28-kDa cysteine protease of Fasciola gigantica adult worms. Vet. Parasitol., 57: 309-318. 
13. HANNA R.E.B., JURA W., 1977. Antibody response of calves to a single infection of Fasciola gigantica determined by an indirect fluorescent antibody technique. Res. vet. Sci., 22: 339-342.

14. HANNA E.R., HUGUES D.L., TAYLOR S.M., 1982. Fasciola hepatica: antibody levels in sheep serum before and after treatment with anthelminthic. Res. vet. Sci., 33: 328-332.

15. HILLYER G.V., SOLER DE GALANES M., 1988. Identification of a 17-kilodalton Fasciola hepatica immunodiagnosis antigen by the enzyme-linked immunoelectrotransfer blot technique. J. clin. Microbiol. 26: $2048-2053$

16. MALONE J.B., 1981. Manual of laboratory technique standard operating procedure. Baton Rouge, LA, USA, Louisiana State University, 29 p.

17. OLDHAM G., 1983. Antibodies to Fasciola hepatica antigens during experimental infections in cattle measured by ELISA, enzyme-linked immunosorbent assay. Vet. Parasitol., 13: 151-158.

\section{Summary}

18. PFISTER K., DAVEAU C., AMBROISE-THOMAS P., 1984. Partial purification of somatic and excretory-secretory products of adult Fasciola hepatica and their application for the serodiagnosis of experimental and natural fascioliasis using an ELISA. Res. vet. Sci., 37: $39-43$

19. RIVERA MARRERO C.A., SANTIAGO N., HILLYER G.V., 1988. Evaluation of immunodiagnostic antigens in the excretory-secretory products of Fasciola hepatica. J. Parasitol., 74: 646-652.

20. SANTIAGO DE WEIL N., HILLYER G., 1988. Antibody profiles by EITB and ELISA of cattle and sheep infected with Fasciola hepatica. J. Parasitol., 74: 810-818.

Reçu le 23.01.2003, accepté le 29.03.2004
Bent Mohamed A., Cheikh D., Thiam E., Jacquiet P. ELISA for Serological Diagnosis of Cattle Fasciolosis due to Fasciola gigantica in Mauritania

Since erecting Diama and Manantali dams, an increase in cattle trematodosis and specially fasciolosis due to Fasciola gigantica was observed in the lower valley of the Senegal River. A serological screen test by ELISA was developed using as antigen the excretory-secretory products of adult liver flukes. The results obtained by ELISA were compared to those obtained by direct examination of the bile ducts of 176 cattle slaughtered in the lower valley of the river. Of the 40 cattle harboring adult liver flukes, 39 were positive by ELISA. In addition, 24 cattle had high antibody titers without having adult flukes in their bile ducts. Twenty-two of the 24 cattle were slaughtered between March and July, period of contamination of the animals, suggesting that the discrepancy between direct examination and ELISA could come from an earlier detection of the infection by ELISA. Most of the animals harboring single infections with other trematodes (Schistosoma bovis or Paramphistomidae) had no anti- $F$. gigantica antibodies. A serological and coprological survey of selected calves exposed to natural infection near the Senegal River confirmed that the infection period occurs between March and July. Moreover, a cross survey of 15 cattle herds in the lower valley of the river showed that two thirds of these herds were infected, with serological prevalences varying from 13 to $33 \%$.

Key words: Cattle - Fasciola gigantica - ELISA - Disease survey - Epidemiology - Senegal River - Mauritania.

\section{Resumen}

Bent Mohamed A., Cheikh D., Thiam E., Jacquiet P. Diagnóstico serológico de la fasciola bovina por Fasciola gigantica mediante ELISA en Mauritania

Desde el Ilenado de las represas de Diama y de Manantali, en el río Senegal, los tremátodos del ganado, entre los cuales la fasciolasis por Fasciola gigantica, han aumentado en forma importante. Se desarrolló un test de rastreo serológico mediante ELISA, utilizando como antígenos los productos de excreción-secreción de las duelas adultas. Los resultados de este test se compararon con la búsqueda directa de las duelas adultas en los canales biliares de 176 bovinos sacrificados en el valle bajo del río. Entre los 40 bovinos portadores de duelas adultas, 39 fueron positivos para el ELISA. Por otro lado, 24 bovinos presentaron títulos de anticuerpos elevados sin presencia de duelas adultas en los canales biliares. En 22 de estos 24 animales, el sacrificio se realizó entre marzo y julio, periodo durante el cual los bovinos se infestan, sugiriendo que lo esencial de la discordancia entre el diagnóstico por ELISA y la búsqueda de duelas adultas provino de un rastreo precoz de la infestación mediante el método ELISA. La mayoría de los animales que presentaron una infestación mono específica por otros tremátodos (Schistosoma bovis o paranfistomos) no presentaron anticuerpos anti $F$. gigantica. El seguimiento serológico y coprológico de una cohorte de terneros expuestos a la infestación natural a proximidad del río Senegal permitió la confirmación de que el periodo de infestación se da entre marzo y julio. Aún más, un estudio transversal sobre 15 hatos de bovinos en el valle bajo del río permitió demostrar que dos tercios de estos hatos se encuentran infestados, con prevalencias serológicas que varían de 13 a 33\%.

Palabras clave: Ganado bovino - Fasciola gigantica - ELISA Encuesta sanitaria - Epidemiología - Río Senegal - Mauritania. 